\title{
De quanta investigação em Química precisa o mundo?
}

\author{
VINCENZO BALZANI *
}

Aimportância da Química numa sociedade civilizada não é bem compreendida pelos políticos, e não é suficientemente apreciada pelo público em geral. De facto, actualmente a Química é pouco considerada no mínimo por três motivos: 1) o mau uso da Química em algumas actividades humanas; 2) a baixa qualidade do ensino da Química nas escolas secundárias; 3 ) a má cobertura pelos meios de comunicação, que exagera os riscos e não fala dos benefícios da Química. 0 termo "quimiofobia" começou mesmo a ser utilizado [1], e a Indústria Química foi forçada a tomar medidas para melhorar a sua imagem pública [2]. 0 s cidadãos dos paises desenvolvidos associam frequentemente a palavra "química" com venenos, poluição e acidentes industriais, e esquecem que gozam de uma elevada qualidade de vida devido às realizações da investigação química: fertilizantes, medicamentos, fibras, combustiveis, plásticos, etc.

A má reputação da Química afasta os estudantes desta disciplina. A falta de compreensão dos políticos limita drasticamente as verbas para investigação.

Estes dois factores levantam questões importantes acerca do futuro da investigação em Química. A falta de estudantes e de financiamento desvaloriza os químicos, e tem outras más consequências como seguidamente se descreve.

A fim de melhorar a imagem da Química, os docentes deveriam fazer mais e melhor no campo da educação. Há dois anos o nosso Departamento decidiu enviar alguns de nós às escolas secundárias em Bolonha, para falar com os estudantes sobre o ilimitado número de perspectivas intelectuais e de aplicações proporcionadas pela Química. Em consequência disto, o número de estudantes a iniciar estudos em Química triplicou.

Todos os investigadores em Química necessitam de compreender melhor o seu papel e a sua potencial função como educadores da sociedade. Eles deveriam ser menos relutantes em falar, e estar mais disponiveis para qualquer iniciativa que possa explicar (de um modo correcto) as brilhantes promessas da Química para o futuro.

0 problema do financiamento insuficiente é mais complexo e mais difícil de manejar. A situação pode ser diferente em paises distintos, mas as considerações seguintes deverão ser suficientemente gerais [3]. 0s políticos argumentam que 0 apoio financeiro para a investigação académica aumenta todos os anos. Contudo, quando os números são corrigidos para a inflação, o verdadeiro aumento (se existir) é muito modesto, e advêm dificuldades devido a dois aspectos menos considerados:

1) 0 número de investigadores em Universidades e Centros de Investigação tem aumentado consideravelmente nos últimos 20 anos. Na maior parte dos países excedeu o dobro. Isto significa que em 1991, há mais do dobro dos investigadores a competir por um montante que não é muito maior do que era em 1971. 0 crescimento da comunidade de investigadores químicos orientou-se em grande parte para campos de investigação novos e essenciais (p. ex. Ciências dos Materiais, Química Bioinorgânica, Química Supramolecular). Deveriamos parar esta expansão natural da Química nestas novas áreas?

2) 0 custo da investigação aumenta continuamente por vários motivos. Os problemas "fáceis" já foram resolvidos e à medida que a nossa compreensão aumenta as questões a responder tornam-se mais complexas. Isso implica um aumento correspondente na sofisticação (e custo) do equipamento necessário para investigar. Quando os mais velhos de nós começaram a investigar, o equipamento mais sofisticado no laboratório era provavelmente um espectrofotómetro manual de feixe simples Beckmann DU. Actualmente um projecto em Fotoquímica dificilmente pode ser desenvolvido sem equipamento controlado por computador. Um laser de corante de modelo recente custa agora três vezes mais (corrigido para a inflação) do que há 15 anos atrás. Além disso, a nova legislação (totalmente justificável) imposta à actividade de investigação, veio reduzir o volume de investigação que pode ser feito com uma determinada verba.

Devemos evidentemente reconhecer que nenhum investigador está alguma vez totalmente satisfeito com 0 seu laboratório, e que por vezes dinheiro é gasto para efectuar expe- riências erradas e comprar equipamento que nunca é usado. Todos nós deveríamos ser mais cuidadosos na utilização dos fundos para a investigação. Apesar destes factos devemos no entanto reconhecer que a investigação em Química iniciou um processo de decrescimento.

Além de ser unicamente uma fonte de preocupação e desencorajamento, o agravar da situação relativa ao financiamento começa a ter outras más consequências na atitude dos químicos na Universidade. Uma parcela cada vez maior do seu tempo é desviada da investigação e dedicada a escrever mais e mais projectos e relatórios numa tentativa de conseguir dinheiro de várias origens. Para além disso, há uma tendência recente para fazer projectos "seguros", evitando riscos elevados, mas também projectos rentáveis: na situação presente o investigador dificilmente se pode permitir envolver-se em investigação que não conduza a publicação rápida, visto que isto significaria mais dificuldades na obtenção de novos fundos. Ainda pior, é-se obrigado a orientar-se, sem se ter a motivação necessária, para temas de investigação que se supõe serem favorecidos pelas agências de financiamento oficiais. Outra consequência não desprezável da competição pelo financiamento é a tentação de exagerar e publicitar mesmo "descobertas" insignificantes.

Da análise anterior seria possivel concluir que há duas maneiras de sair da presente situação: um aumento do orçamento para investigação em Química, ou uma redução do número de investigadores em Química, de modo a ter uma menor dispersão (e portanto um melhor uso) dos fundos limitados que estão de momento disponiveis. antes de escolher uma destas duas opções, devemos antes responder a uma importante questão: de quanta investigação em Química precisa o mundo?

Entre todas as ciências fundamentais a Química é a mais ligada à realidade perceptivel: a investigação em Física Nuclear e Astronomia é muito interessante de um ponto de vista básico e pode certamente conduzir a novas descobertas fundamentais mas não está relacionada com a nossa experiência directa e necessidades 
quotidianas. A Química é a mais central de entre as disciplinas científicas. Qualquer ligação possivel entre a Biologia e a Física é feita através da Química. A Biologia de facto, é no limite redutivel à Química. A Física do Estado Sólido, a Ciência dos Materiais, a Engenharia Química, as Ciências da Terra e áreas afins, são em grande parte baseadas na Química. Em consequência, a Química actualmente é muito mais que uma ciência altamente especializada capaz de explicar comofunciona a natureza e resolver uma variedade de problemas.

A Química de certo modo, pode ser encarada como uma ciência trasndisciplinar, tal como a Matemática: é uma ciência que fornece meios essenciais e uma linguagem fundamental para compreender totalmente outras disciplinas científicas [4].

Parece óbvio, portanto, que não nos podemos permitir diminuir a quantidade de investigação em Química. Isso seria equivalente a um crime contra a humanidade. 0 s problemas globais mais importantes (alimentação, saúde, energia, ambiente) não podem ser resolvidos sem a Química. Sem a Química não haveria esperança de diminuir as diferenças entre os países desenvolvidos e em desenvolvimento. As experiências do passado mostram que a investigação química compensa. Portanto todos os esforços devem ser feitos para aumentar a quantidade e a qualidade da investigação em Química. Para efeitos práticos, isto só será possível se recursos financeiros mais abundantes forem tornados disponiveis.

$\mathrm{Na}$ maior parte dos países, evidentemente que mais dinheiro para investigação em Química significaria menos dinheiro para outras necessidades. Num clima de solicitações crescentes aos orçamentos públicos, este é sem dúvida um problema dificil de resolver. Necessitamos de mais cidadãos que se preocupem com o conjunto da humanidade, e de mais políticos que não se preocupem com as próximas eleições. 0 problema, contudo, existe e tem que ser enfrentado. Enquanto cada país pode tentar encontrar uma solução original, eu gostava de sugerir duas possibilidades que parecem viáveis na maior parte dos paises desenvolvidos:

a) Não há motivo na presente situação internacional (nem, na minha opiniāo existiria anteriormente), para atribuir enormes recursos financeiros a despesas militares; por exemplo, a soma recentemente gasta para comprar doze bombardeiros Harrier de deslocamento vertical para a Marinha Italiana é quatro vezes maior que a verba gasta anualmente por todos os organismo de investigação italianos
(MURST, CNR, ENEA, ISS, etc.) para apoiar a investigação em Química.

b) independentemente do facto do orçamento total para a investigação científica poder ou não ser aumentado o problema de uma distribuição de fundos justa e mais inteligente entre as várias disciplinas não pode continuar a ser ignorado por mais tempo.

A última sugestão merece alguns comentários adicionais. No seu bem conhecido relatório "Opportunities in Chemistry" [5] Pimentel salientou que "actualmente a imagem pública da ciência é ainda muito influenciada pelo efeito de reverberação do grande Projecto Manhattan que nos trouxe a bomba atómica e o grande Projecto Apollo que nos permitiu pôr um pé na Lua". Daique quantidades exorbitantes de dinheiro continuem a fluir para a "Big Science" (grande ciência): projectos em Física Nuclear, Espaço e Astronomia. Em contraste, a investigação em projectos de "ciência pequena" são em grande parte insuficientemente financiados.

Foi estimado que nos EUA [5] o custo médio para produzir um Doutor em Física é cerca de sete vezes mais elevado do que o necessário para produzir um Doutor em Química. $\mathrm{Na}$ maior parte dos paises ocidentais, os fundos para investigação atribuídos à Física e Ciências do Espaço é pelo menos dez vez maior que 0 atribuído à Química. Os números em Itália (para o ano de 1991) são os seguintes: Espaço, $23 \%$, Física, $18 \%$, Química, 4, $2 \%$.

Ao comentar estes números, um documento recente da Organização para a Cooperação e Desenvolvimento Económico (OCDE) afirma: "Estamos particularmente surpreendidos pela quantidade de recursos atribuídos à 'grande ciência' em Itália..."; um grande ênfase na "grande ciência" pode funcionar em detrimento da "pequena ciência".

Deve também ser lembrado que a investigação em Química é não só muito barata, mas também mais produtiva para as necessidades da humanidade, que a grande investigação sobre o Espaço ou Física Nuclear. Tal como notado por Pimentel, o segredo da alta produtividade da investigaçāo em Química é o seu "modus operandi", que é baseado num grande número de pequenos projectos onde a iniciativa e a criatividade pessoal têm um pael decisivo. Infelizmente, só a "grande ciência" parece valer a pena para os políticos e membros das organizações. Pimentel[5] também salientou que "nós estamos numa era em que os directores das agências de financiamento federais dos EUA, admitem com candura que acreditam ser mais fácil a argumentação para um enorme aumento de financiamento para apoiar uma grande máquina ou um projecto massivo, que para um incremento mais pequeno para estimular muitos pequenos projectos com expectativas comparáveis ou maiores em relação a novas descobertas e avanços científicos, que vão seguramente responder às necessidades da sociedade. Esta atitude é largamente espalhada na maior parte dos países. Se ela não mudar, um perigo adicional advém: a investigação em química será forçada a seleccionar temas artificiais ou projectos com títulos pomposos a fim de sobreviver. Seria uma pena porque a diversidade é ainda uma das maiores virtudes da Química.

Uma investigação em Química adequadamente financiada fornecer-nos-ia materiais com propriedades excepcionais e mais eficazes, medicamentos menos caros, novas fontes de energia, e muito mais coisas [6] porque a manipulação e caracterização da matéria numa perspectiva atómica e molecularfornece os fundamentos para um número ilimitado de perspectivas intelectuais e práticas [7]. Afinal de contas, as investigações sobre a origem da vida e a conversão fotoquímica da energia solar, não são certamente menos importantes e fascinantes que as investigação sobre a origem do universo e a fusão nuclear.

Para terminar, uma palavra de aviso. As descobertas científicas podem ser usadas para o bem e para o mal. Qualquer que seja a área de investigação científica a desenvolver, como cidadāos e cientistas devemos manter os nossos olhos abertos para impedir qualquer má utilização de novas descobertas.

*Professor da Universidade de Bolonha. Publicado originalmente em EPA Newsletter 43 (1991) 1.

Traduzido por M. Z., com a autorização do autor e da EPA

\section{REFERÊNCIAS}

[1] G.B. Kauffmann, Chemistry in Britain, 512 (1991).

[2] D. Goskell, Chemistry in Britain, 485 (1991). [3] L.M. Lederman, The end of a frontier? Supplement to Science, January 1991.

[4] A.M. Liquori, Sapere, Agosto/Setembro $1991,34$.

[5] G. Pimentel, Opportunities in Chemistry, Washinghton DC, National Academy, 1985. [6] G. Whiterides, Angew. Chem. Intern. Ed. Engl., 29 (1990) 1209.

[7] K.E. Drexler, Engines of Creation, Anchor Books, Doubleday, N.Y., 1990 